\title{
CONHECIMENTO DE DISCENTES DE ENFERMAGEM ACERCA DOS PROTOCOLOS DE SEGURANÇA DO PACIENTE
}

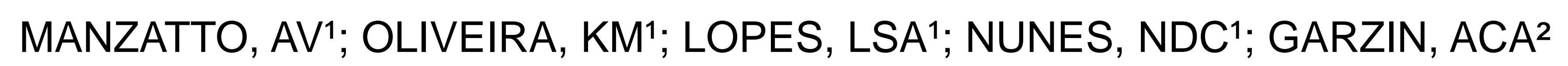

\section{INTRODUÇÃ̃O}

Uma das estratégias do Programa Nacional de Segurança do Paciente (PNSP), baseia-se na elaboração e apoio à implementação de protocolos, guias e manuais de segurança do paciente nas instituições de saúde. Para que a qualidade e segurança do paciente permeie estas instituições, faz-se necessário desenvolver o conhecimento, as habilidades e as atitudes sobre tais temáticas na formação dos futuros profissionais de saúde, de modo que sejam capazes de gerenciar sua atuação com base nas melhores evidências e com foco nos melhores resultados assistenciais.

\section{OBJETIVOS}

- Avaliar o conhecimento dos graduandos de enfermagem em relação aos protocolos de segurança do paciente;

- Identificar em qual momento da graduação esses protocolos são abordados.

\section{MÉTODO}

Pesquisa exploratória, descritiva e quantitativa

População: Graduandos do curso de enfermagem

Questionário elaborado a partir dos protocolos do PNSP, aplicado entre junho e agosto de 2018

Aspectos éticos: Aprovação no COEP ( $\left.n^{\circ} 2.693 .350\right)$ e assinatura do TCLE

Inclusão: todos os graduandos de enfermagem da instituição cenário do estudo $(\mathrm{N}=630)$

Exclusão: experiência profissional como técnicos ou auxiliares de enfermagem

\section{RESULTADOS}

Participaram da pesquisa 404 alunos (64\% do total), sendo que 341 (84\%) frequentavam o curso no período matutino e $63(16 \%)$ no período noturno e que demonstraram algum conhecimento acerca dos protocolos.
Gráfico 1: A higienização das mãos é fundamental para prevenir e controlar as Infecções Relacionadas à Assistência à Saúde.

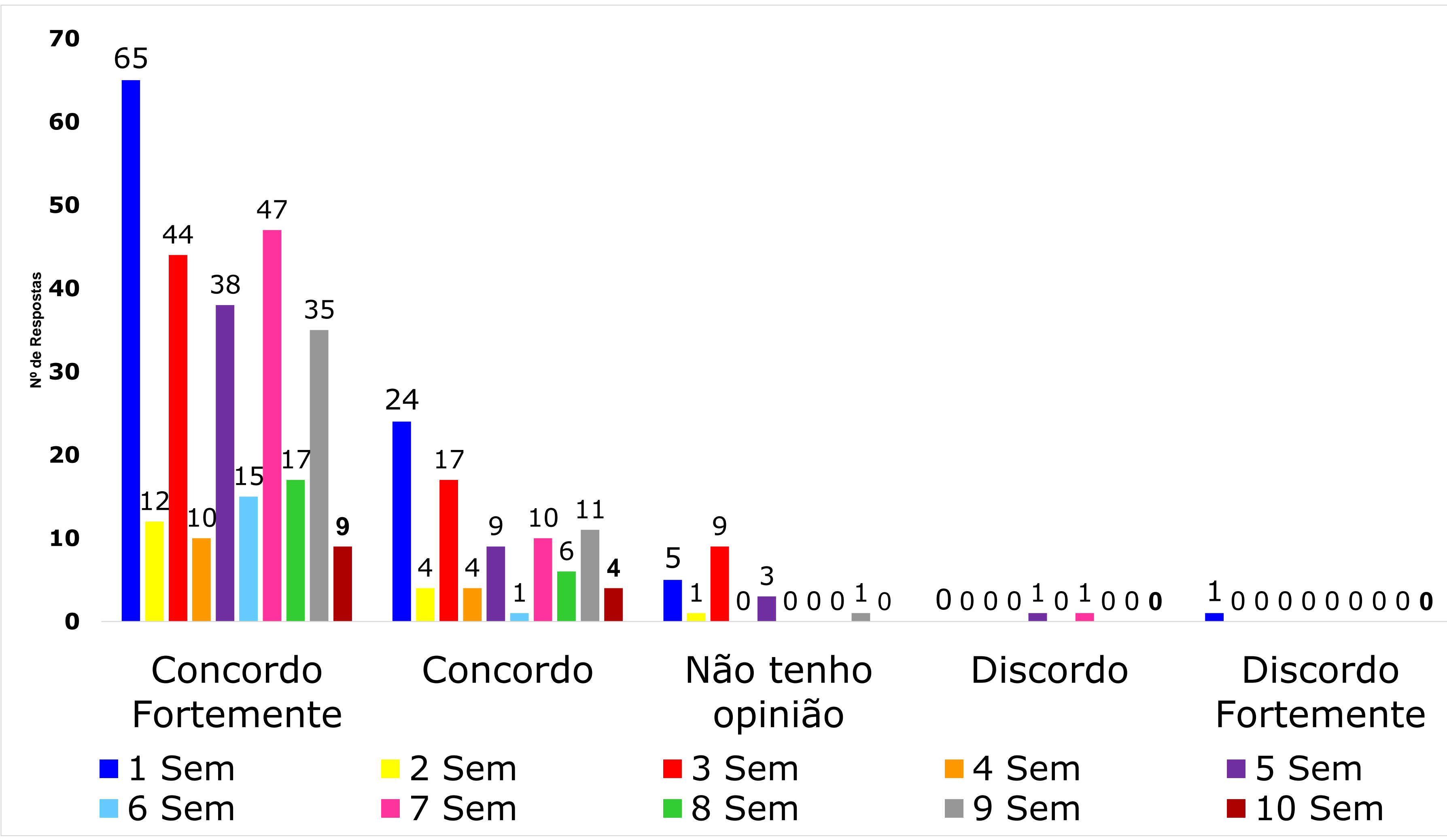

Gráfico 2: A lista de verificação de segurança cirúrgica deve ser realizada em três momentos: antes da indução anestésica, antes da incisão cirúrgica e antes do paciente sair da sala de cirurgia.
45
40

40
35

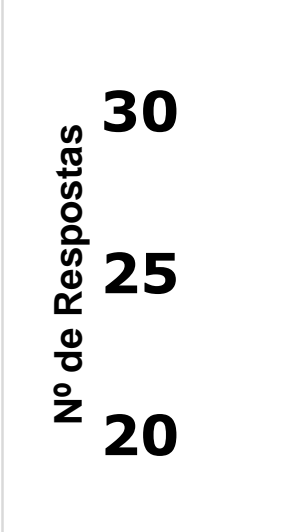

15

10
5

5

0

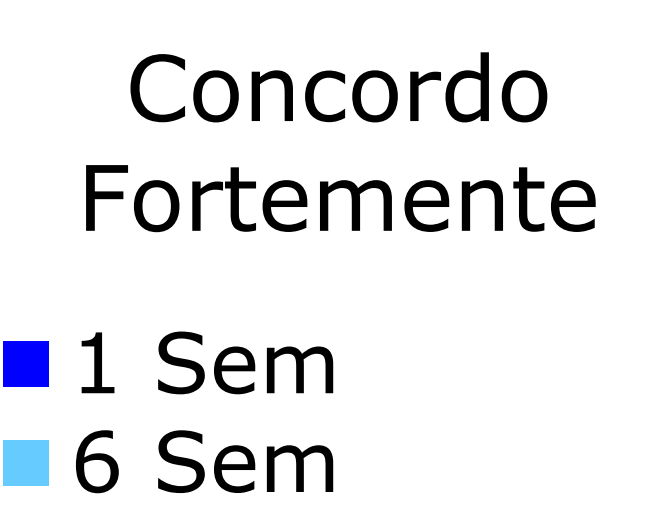

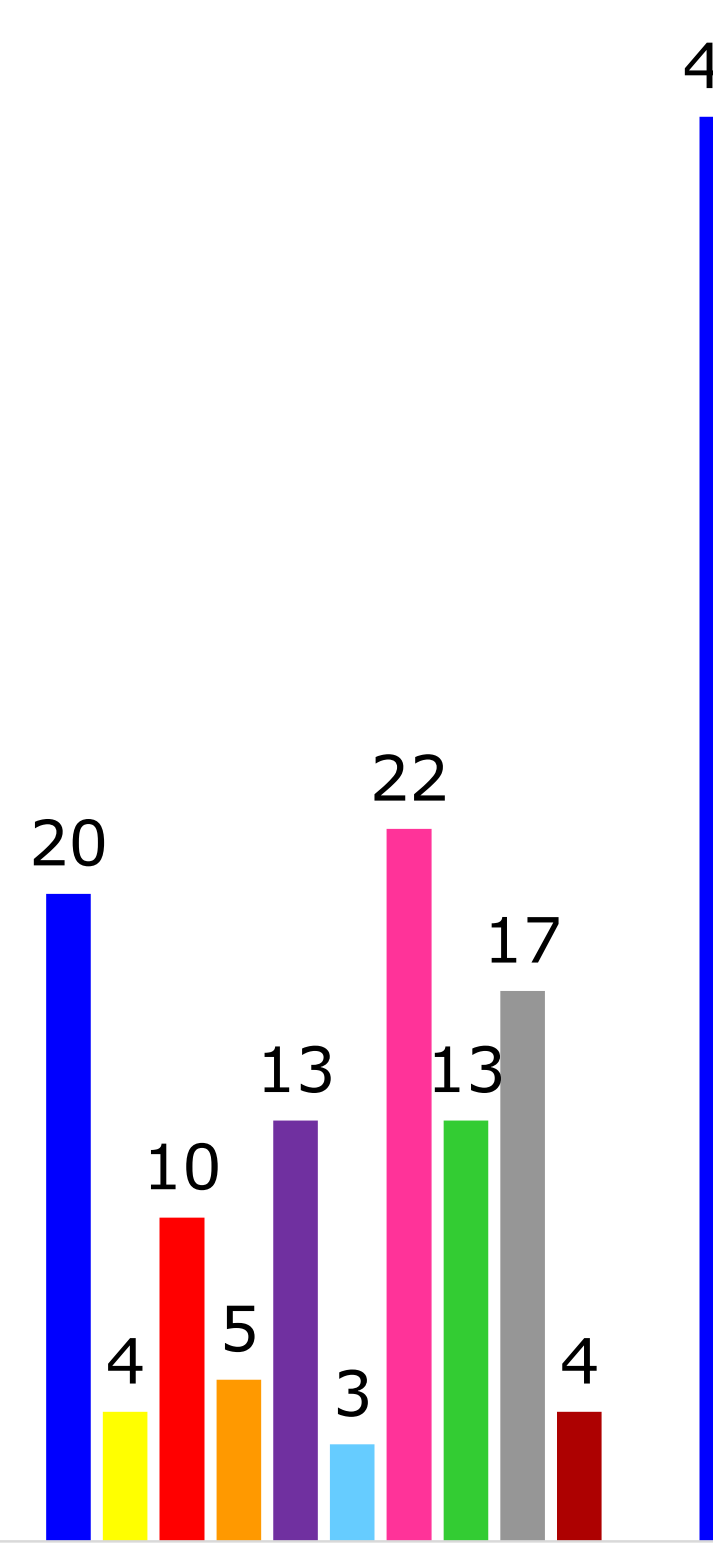

Concordo

2 Sem

7 Sem

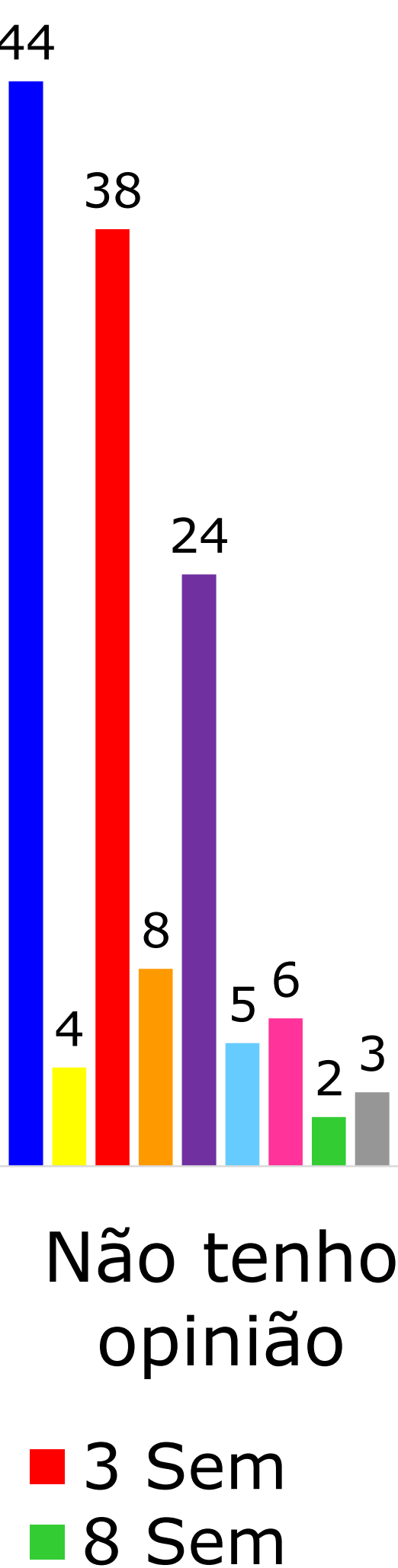

${ }_{1}^{10} 4$

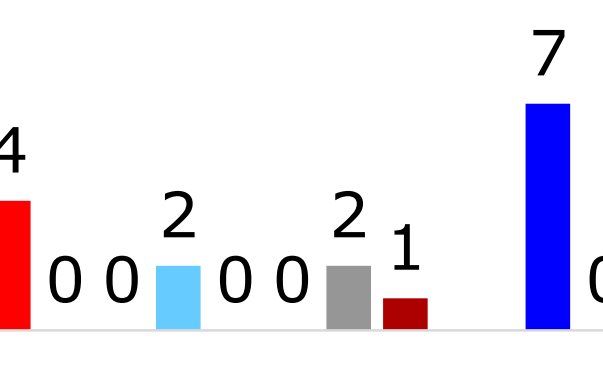

Discordo

4 Sem 9 Sem
$0000^{1} 0011$

Discordo

Fortemente

- 5 Sem - 10 Sem

Ainda que os protocolos não sejam discutidos de forma literal, estão inseridos no processo de aprendizagem de enfermagem, juntamente com o cuidar baseado em evidências e com a segurança do paciente.

\section{CONCLUSÃO}

Apesar de não identificarmos precisamente o momento, os protocolos de segurança do paciente foram abordados durante a graduação em enfermagem culminando com maior conhecimento dos alunos nos últimos semestres. 0 desenvolvimento de conhecimento, habilidades e atitudes acerca deste conteúdo contribui no desenvolvimento de competências dos futuros enfermeiros e, possivelmente, em melhores resultados assistenciais. 